\title{
PREPARO DO SOLO E ADUBAÇÃO NITROGENADA NA PRODUÇÃO DE GRÃOS E MATÉRIA SECA E ACÚMULO DE NUTRIENTES PELO MILHO'
}

\author{
LUIZ ARNALDO FERNANDES ${ }^{2}$, CARLOS ALBERTO VASCONCELLOS ${ }^{3}$, \\ ANTONIO EDUARDO FURTINI NETO ${ }^{4}$, RENATO ROSCOE ${ }^{5}$ e GERALDO APARECIDO DE AQUINO GUEDES ${ }^{6}$
}

RESUMO - Avaliou-se o efeito de sistemas de preparo do solo e de doses de nitrogênio, na produção de matéria seca, grãos e palhada, bem como no acúmulo de $\mathrm{N}, \mathrm{P}, \mathrm{K}, \mathrm{Ca}, \mathrm{Mg}, \mathrm{S}$ e $\mathrm{Zn}$, por plantas de milho (Zea mays L.). O experimento foi conduzido, sob irrigação, em um Latossolo Vermelho-Escuro sob vegetação de cerrado, em área experimental da Embrapa-Centro Nacional de Pesquisa de Milho e Sorgo, Sete Lagoas, MG. Os sistemas de preparo do solo estudados foram: plantio direto, plantio convencional com arado de discos, e plantio convencional com arado de aiveca. As doses de nitrogênio, 0, 60, 120 e $240 \mathrm{~kg} \mathrm{ha}^{-1}$ de $\mathrm{N}$, foram aplicadas em cobertura. As maiores produções de matéria seca de grãos e de palhada e de acúmulo de nutrientes foram obtidas sob o sistema de plantio direto. Na dose de $60 \mathrm{~kg} \mathrm{ha}^{-1}$ de $\mathrm{N}$, ocorreu a maior eficiência da utilização do $\mathrm{N}$ pela cultura, constatada pela maior recuperação do $\mathrm{N}$ aplicado.

Termos para indexação: Zea mays, nutrição, cerrado.

\section{SOIL PREPARATION AND NITROGEN FERTILIZATION IN CORN PRODUCTION AND NUTRIENTS ACCUMULATION}

\begin{abstract}
The effects of soil preparation and doses of nitrogen on grain and straw dry matter production and N, P, K, Ca, Mg, S and Zn accumulation by corn plants (Zea mays L.) cultivated under irrigation were evaluated in a field experiment in a Dark Red Latosol (Oxisol), originally under cerrado vegetation, at Embrapa-Centro Nacional de Pesquisa de Milho e Sorgo experimental station, in Sete Lagoas, MG, Brazil, from November, 1995 to June, 1996. The soil preparation systems studied were: no till, conventional till with disk plow and conventional till with moldboard plow. The nitrogen doses were: 0 , 60,120 and $240 \mathrm{~kg} \mathrm{ha}^{-1} \mathrm{~N}$, applied in cover. The highest productions of grains and straw dry matter and nutrients accumulation were obtained in the no till system. In the doses of $60 \mathrm{~kg} \mathrm{ha}^{-1} \mathrm{~N}$, the greatest efficiency and the highest recover of applied $\mathrm{N}$ by the crop occurred.
\end{abstract}

Index terms: Zea mays, nutrition, savannah.

\section{INTRODUÇÃO}

Do total produzido no Brasil em cereais e oleaginosas, o milho é o produto que mais se destaca em volume de produção. Segundo Pinazza (1993),

\footnotetext{
${ }^{1}$ Aceito para publicação em 3 de fevereiro de 1999.

${ }^{2}$ Eng. Agr., Prof. Substituto, Dep. de Ciência do Solo, Universidade Federal de Lavras (UFLA), Caixa Postal 37, CEP 37200-000 Lavras, MG. E-mail: larnaldo@esal.ufla.br

${ }^{3}$ Eng. Agr., Embrapa-Centro Nacional de Pesquisa de Milho e Sorgo (CNPMS), CEP 37200-000 Sete Lagoas, MG.

${ }^{4}$ Eng. Agr., Prof. Adjunto, UFLA.

${ }^{5}$ Eng. Agr., aluno do Curso de Pós-graduação em Solos e Nutrição de Plantas, UFLA.

${ }^{6}$ Eng. Agr., Prof. Titular, UFLA.
}

de cada $3 \mathrm{~kg}$ colhidos, mais de $1 \mathrm{~kg}$ é de milho. Apesar de o país ser um dos maiores produtores mundiais dessa cultura, a produtividade ainda é baixa (cerca de $2.300 \mathrm{~kg} / \mathrm{ha}$ ), sendo superada inclusive em alguns países do terceiro mundo, de nível tecnológico inferior (Büll, 1993).

OCerrado brasileiro, com uma área de $1.800 .000 \mathrm{~km}^{2}$, $21 \%$ do território nacional, constitui uma opção para o cultivo do milho, graças às características químicas e físicas do solo. A classe de solos dominante é a dos Latossolos, que ocupa em torno de $55 \%$ da área; além de serem esses os solos mais abundantes, são os mais utilizados (Ker et al., 1992), em face da grande facilidade que oferecem ao uso de máquinas. No entanto, dado o longo período de 
estiagem que ocorre na região, os agricultores não utilizam eficientemente tais solos. $\mathrm{O}$ uso contínuo de grade aradora e a pulverização excessiva da camada superficial do solo têm levado ao aparecimento de camadas compactadas e selamento superficial dos solos, com conseqüente aumento da erosão e queda de produtividade.

Uma das conseqüências do cultivo é a queda dos teores de matéria orgânica do solo, que está intimamente relacionada com os principais fatores do solo, entre eles, a soma de bases e a CTC, sendo portanto a parte mais ativa em solos de baixa fertilidade (Pereira \& Peres, 1986).

A atividade biológica do solo é intensificada na presença de matéria orgânica em interação com os nutrientes adicionados, favorecendo a estabilidade dos agregados do solo, a retenção de umidade e a melhoria do processo de infiltração de água (Cardoso, 1993). Segundo este autor, passou-se a enfatizar, nas área de cerrado, a manutenção da estrutura do solo por meio do plantio direto, cultivo mínimo, uso de escarificador, e preservação dos restos culturais na superfície do solo. O preparo excessivo é desaconselhável, pois além de prejudicar o solo, onera os custos da cultura (Embrapa, 1993).

As práticas de cultivo visando à produção agrícola sustentável devem minimizar as limitações do solo e do clima, assegurando produções crescentes, além de conservar os recursos naturais e proteger o meio ambiente (Morrison \& Chichester, 1994).

Os efeitos do sistema de preparo nas propriedades dos solos e os favorecimentos ou limitações que esse ambiente impõe às plantas cultivadas manifestam-se em graus de intensidade variáveis, dependendo dos sistemas de preparo empregado e das características do próprio solo (Cardoso, 1993). Se o preparo do solo afetar sua aeração, afetará a porosidade, a densidade, e, conseqüentemente, a morfologia do sistema radicular (Holanda, 1996).

Além dos cuidados a serem tomados durante o preparo do solo para que se não onere o custo da produção, a adubação nitrogenada deve ser empregada de modo a maximizar a produtividade (Pang et al., 1997), visto que este nutriente está sujeito a perdas no sistema solo em função de sua dinâmica. Segundo Raij (1991), a adubação nitrogenada em excesso pode causar um desenvolvimento vege- tativo excessivo, em detrimento da produção de tubérculos ou raízes, proporcionar folhas mais suculentas e susceptíveis a doenças, reduzir a produção de frutos e o teor de açúcares, e predispor a cultura ao acamamento. Ainda, segundo este autor, a adubação nitrogenada é complexa e deve ser feita com cuidado, pois se, de um lado, a falta de nitrogênio pode limitar seriamente a produção, por outro, o excesso pode reduzi-la.

O objetivo do presente trabalho foi avaliar o efeito de diferentes sistemas de preparo do solo e de doses crescentes de nitrogênio na produção de milho e no acúmulo de N, P, K, Ca, Mg, S e Zn, por esta cultura, quando cultivada em um Latossolo VermelhoEscuro fase cerrado.

\section{MATERIAL E MÉTODOS}

O experimento foi desenvolvido em condições de campo em área experimental da Embrapa-Centro Nacional de Pesquisa de Milho e Sorgo (CNPMS), em Sete Lagoas, MG, num Latossolo Vermelho-Escuro, epidistrófico endoálico, A moderado, textura muito argilosa, relevo suave ondulado, fase cerrado, de acordo com o Sistema Brasileiro de Classificação, sendo o clima do tipo AW, segundo a classificação de Köppen. A caracterização química e física do solo estudado encontra-se na Tabela 1.

Os sistemas de preparo do solo avaliados foram: plantio direto (Direto), preparo convencional com arado de disco e grade niveladora (Disco) e preparo convencional com arado de aiveca e grade niveladora (Aiveca). Nos sistemas Disco e Aiveca, foram realizadas uma aração com os respectivos arados e duas gradagens por cultivo. Os sistemas de preparo do solo vêm sendo adotados desde 1987, na área experimental, que é cultivada anualmente com milho e feijão.

O milho, variedade Cargil-805, foi plantado em 25/11/95. A adubação de plantio, comum a todos os tratamentos foi de $400 \mathrm{~kg} \mathrm{ha}^{-1}$ de 4-20-20. A adubação nitrogenada foi realizada aos 45 dias após o plantio, utilizando as doses de $0,60,120$ e $240 \mathrm{~kg} \mathrm{ha}^{-1}$ de $\mathrm{N}$ na forma de uréia.

O delineamento experimental utilizado foi em blocos ao acaso, arranjados num esquema fatorial de $3 \times 4$ (três sistemas de preparo de solos e quatro doses de N), com quatro repetições. Cada parcela experimental tinha uma área total de $180 \mathrm{~m}^{2}$ (7,2 m x $\left.25 \mathrm{~m}\right)$, com oito linhas espaçadas de $0,9 \mathrm{~m}$.

O sistema de irrigação utilizado foi o de aspersão; a necessidade de irrigação foi estimada através do balanço de 
água no solo. A colheita foi realizada no dia $8 / 5 / 96$, com os grãos apresentando um teor médio de umidade de $12 \%$. A área útil utilizada para estimar a produção foi de $27 \mathrm{~m}^{2}$ de dimensão. Após a contagem do número de plantas, colheram-se separadamente as espigas, colmos e folhas. Para determinação da matéria seca e de nutrientes, a parte aérea das plantas de milho foi dividida em: folhas+palha da espiga, colmo+pendão ou inflorescência masculina, sabugo e grãos. Para o cálculo da produção de matéria seca total e acúmulo total de nutrientes na palhada, foram somadas as produções de matéria seca e de nutrientes acumulados na folha+palha, colmo+pendão e sabugo. $\mathrm{O} N$ total foi determinado pelo método semimicro-Kjeldahl, e os demais nutrientes por espectrometria de emissão de plasma.

Os efeitos dos tratamentos na produção de matéria seca e nos nutrientes acumulados foram avaliados pelas análises de variância; os sistemas de preparo dos solos foram comparados pelo teste de Tukey, a 5\% de significância, e as doses de N, por equações de regressão polinomial, ajustadas para a produção de matéria seca em função das doses de $\mathrm{N}$ aplicadas.

A recuperação aparente do $\mathrm{N}$ fertilizante foi estimada pelo método da diferença, conforme Coelho et al. (1992), considerando a diferença entre o $\mathrm{N}$ total absorvido pelas plantas das parcelas que receberam adubação nitrogenada em cobertura $(\mathrm{Nc})$ e das parcelas sem adubação em co- bertura (Nsc), dividida pela quantidade de $\mathrm{N}$ aplicado em cobertura (Nac), que pode ser expresso pela seguinte equação:

$\% \mathrm{~N}$ recuperado $=(\mathrm{Nc}-\mathrm{Nsc}) 100 / \mathrm{Nac}$.

A eficiência de utilização (EU) de nutrientes pela parte aérea das plantas de milho foi calculada pela seguinte expressão (Siddiqi \& Glass, 1981):

$\mathrm{EU}=(\mathrm{kg} \text { de matéria seca da parte aérea })^{2} /(\mathrm{mg}$ de nutrientes na matéria seca da parte aérea).

\section{RESULTADOS E DISCUSSÃO}

As maiores produções de matéria seca de palhada (matéria seca da folha + palha, colmo + pendão e sabugo) e de grãos e as maiores médias foram obtidas no sistema Direto, independentemente da dose de $\mathrm{N}$ aplicada, enquanto as menores produções foram verificadas no sistema Aiveca (Fig. 1).

As produções de palhada e de grãos aumentaram de forma quadrática com o aumento das doses de $\mathrm{N}$ (Fig. 1). Através das equações de regressão estimou-se a dose de $\mathrm{N}$ para $90 \%$ da produção máxima, que pode ser considerada como a dose de máxima eficiência econômica (Hoffmann, 1992). As doses

TABELA 1. Características químicas e físicas do Latossolo Vermelho-Escuro após oito anos de cultivo, em duas profundidades de amostragem, nos três sistemas de preparo do solo, antes do plantio do milho ${ }^{1}$.

\begin{tabular}{|c|c|c|c|c|c|c|}
\hline \multirow[t]{2}{*}{ Características } & \multicolumn{2}{|c|}{ Direto } & \multicolumn{2}{|c|}{ Disco } & \multicolumn{2}{|c|}{ Aiveca } \\
\hline & $0-7,5 \mathrm{~cm}$ & $7,5-15 \mathrm{~cm}$ & $0-7,5 \mathrm{~cm}$ & $7,5-15 \mathrm{~cm}$ & $0-7,5 \mathrm{~cm}$ & $7,5-15 \mathrm{~cm}$ \\
\hline pH água & 6,40 & 6,30 & 6,25 & 6,33 & 6,13 & 6,05 \\
\hline $\mathrm{H}^{+}+\mathrm{Al}^{3-}\left(\mathrm{cmol}_{\mathrm{c}} \mathrm{dm}^{-3}\right)$ & 2,23 & 3,48 & 2,63 & 2,88 & 3,00 & 3,62 \\
\hline $\mathrm{Al}^{3-}\left(\mathrm{cmol}_{\mathrm{c}} \mathrm{dm}^{-3}\right)$ & - & - & - & - & - & - \\
\hline $\mathrm{Ca}^{2+}\left(\mathrm{cmol}_{\mathrm{c}} \mathrm{dm}^{-3}\right)$ & 7,75 & 5,98 & 7,07 & 6,95 & 6,33 & 5,89 \\
\hline $\mathrm{Mg}^{2+}\left(\mathrm{cmol}_{\mathrm{c}} \mathrm{dm}^{-3}\right)$ & 1,49 & 0,89 & 1,06 & 1,01 & 1,10 & 1,02 \\
\hline $\mathrm{K}\left(\mathrm{mg} \mathrm{kg}^{-1}\right)$ & 270,00 & 154,75 & 272,50 & 179,00 & 234,50 & 142,75 \\
\hline $\mathrm{P}\left(\mathrm{mg} \mathrm{kg}^{-1}\right)$ & 27,50 & 28,25 & 37,00 & 36,75 & 32,75 & 29,50 \\
\hline $\mathrm{S}\left(\mathrm{cmol}_{\mathrm{c}} \mathrm{dm}^{-3}\right)$ & 9,93 & 7,27 & 8,83 & 8,42 & 8,03 & 7,28 \\
\hline $\mathrm{t}\left(\mathrm{cmol}_{\mathrm{c}} \mathrm{dm}^{-3}\right)$ & 9,93 & 7,27 & 8,83 & 8,42 & 8,02 & 7,28 \\
\hline $\mathrm{T}\left(\mathrm{cmol}_{\mathrm{c}} \mathrm{dm}^{-3}\right)$ & 12,16 & 10,75 & 11,46 & 11,30 & 11,03 & 10,90 \\
\hline $\mathrm{m}(\%)$ & - & - & - & - & - & - \\
\hline V $(\%)$ & 82 & 68 & 77 & 75 & 73 & 67 \\
\hline Argila $\left(\mathrm{g} \mathrm{kg}^{-1}\right)$ & 800 & 800 & 800 & 800 & 800 & 800 \\
\hline Silte $\left(\mathrm{g} \mathrm{kg}^{-1}\right)$ & 60 & 90 & 70 & 70 & 70 & 70 \\
\hline Areia $\left(\mathrm{g} \mathrm{kg}^{-1}\right)$ & 140 & 110 & 130 & 130 & 130 & 130 \\
\hline Mat. orgânica $\left(\mathrm{g} \mathrm{kg}^{-1}\right)$ & 45,9 & 36,5 & 41,1 & 40,7 & 38,7 & 39,1 \\
\hline
\end{tabular}

${ }^{1}$ Análises realizadas nos laboratórios da Embrapa-CNPMS, Sete Lagoas, MG. 
de $\mathrm{N}$ para a produção máxima de grãos e equivalente a $90 \%$ da máxima, calculadas pelas equações de regressão, foram: 147 e 70; 156 e 71; e 168 e $73 \mathrm{~kg} \mathrm{ha}^{-1}$, para os sistemas Direto, Disco e Aiveca, respectivamente. Verifica-se que a dose para $90 \%$ da produção máxima (máxima eficiência econômica) ficaram bem abaixo das doses mais elevadas testadas, o que está de acordo com a chamada "Lei dos incrementos decrescentes" (Raij, 1991). Na prática, o uso da dose de N para a obtenção da produção máxima certamente não seria econômico, dada a necessidade de uma grande dose de $\mathrm{N}$ para um aumento na produção de apenas $10 \%$, em relação a $90 \%$ da produção máxima.

A maior produtividade de milho no sistema Direto pode ser atribuída a uma melhoria nas propriedades químicas, físicas e biológicas do solo. Verificou-se, ao longo dos oitos anos de cultivo do solo, um pequeno aumento dos valores de $\mathrm{pH}, \mathrm{Ca}, \mathrm{Mg}, \mathrm{S}$, t e T na camada superficial (0 a 7,5 cm) do solo sob o sistema Direto em relação aos sistemas Disco e Aiveca (Tabela 1). Também Muzilli (1985) e Sidiras
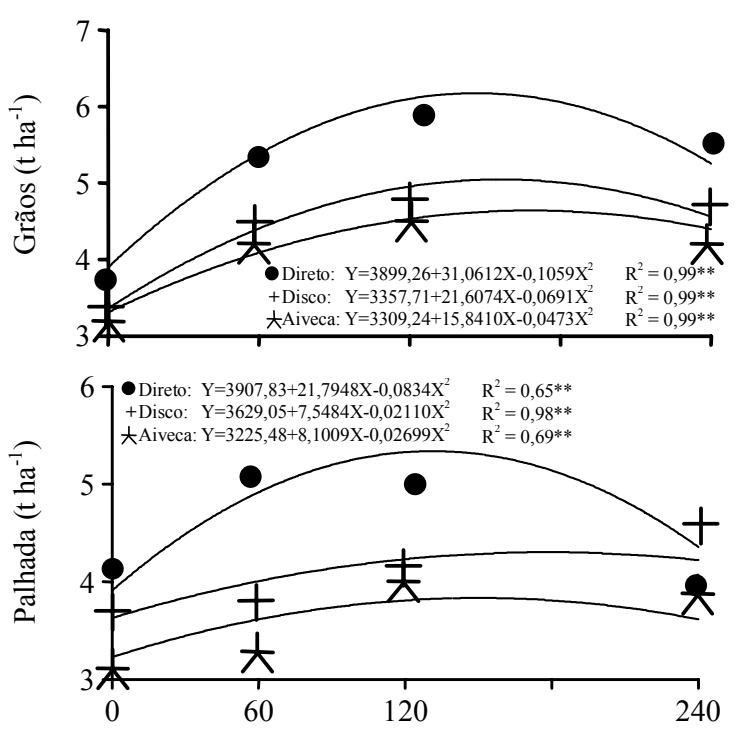

Dose de nitrogênio aplicada $\left(\mathrm{kg} \mathrm{ha}^{-1}\right)$

FIG. 1. Produção de matéria seca e de grãos de plantas de milho cultivadas em diferentes sistemas de preparo de solo e doses crescentes de nitrogênio.
\& Pavan (1985), verificaram melhorias nas propriedades químicas de solos sob plantio direto, quando comparados aos do solo sob plantio convencional, tendo, assim, contribuído para a maior produção daquele sistema.

O teor de matéria orgânica do solo na profundidade de 0-7,5 cm no sistema Direto, após oito anos da instalação, apresentou-se ligeiramente superior aos demais sistemas estudados. A pequena acumulação de matéria orgânica no sistema de plantio direto do presente estudo, em relação aos do sul do país, pode ser atribuída à rápida mineralização dos restos culturais em função das altas temperaturas e umidade. Maria \& Castro (1993a, 1993b) estudando a influência de sistemas de preparo do solo, de sucessão e de rotação de culturas sobre os teores de $\mathrm{P}, \mathrm{K}$ e matéria orgânica, em um Latossolo Roxo, em Campinas, SP, não observaram diferenças significativas nos teores médios de matéria orgânica na camada arável, e atribuíram esse fato às condições climáticas da região, com verão quente e úmido e inverno seco, além do efeito da temperatura, condições estas que favorecem a rápida mineralização da matéria orgânica do solo. É interessante destacar, ainda, que Gregorich et al. (1996) e Liang \& MacKenzie (1992) verificaram aumentos nos teores de matéria orgânica com a adição de $\mathrm{N}$ em solos cultivados continuamente com milho, em relação aos que não receberam adubação.

Apesar da pequena diferença de teores de matéria orgânica encontrada em solos submetidos a diferentes sistemas de preparo, a dinâmica desta deve ser maior no sistema Direto, o que pode ser constatado pela maior quantidade de $\mathrm{N}$ imobilizado na biomassa microbiana (Tabela 2). De acordo com Janssen (1984) e Hsieh (1992) a matéria orgânica fresca do solo é mais ativa biológica e quimicamente, e seus componentes estão mais sujeitos a alterações com o manejo do solo. Follett \& Schimel (1989) verificaram que o aumento da intensidade de cultivo do solo reduz sua capacidade em imobilizar e reter $\mathrm{N}$ mineral, pela redução do $\mathrm{C}$ disponível para ser utilizado como substrato para o crescimento microbiano. Além disso, sistemas de manejo do solo e de culturas, que provocam menores alterações e que permitem a manutenção de teores de matéria orgânica mais elevados, favorecem a 
população microbiana (Siqueira et al., 1994). De acordo com este autor, a imobilização de $\mathrm{N}$ na biomassa torna a reciclagem desse elemento mais vagarosa, porém mais eficiente, quando comparada àquela incorporada através de arações, escarificações e gradagens. Roscoe (1997), neste mesmo experimento, verificou maior atividade da urease na camada de 0-7,5 cm no sistema Direto, atribuindo este fato à maior atividade biológica neste sistema.

Uma provável melhoria nas propriedades físicas do solo sob o sistema Direto, como o aumento da porosidade e do armazenamento de água (Hubbard \& Jordan, 1996), que não foram objeto de estudo do presente trabalho, pode também ter contribuído para a maior produção neste sistema. Centurion \& Dematê (1985) observaram que o sistema de semeadura direta proporcionou maior homogeneidade estrutural do solo, enquanto o aumento da intensidade de preparo do solo provocou acentuadas alterações nas suas propriedades físicas, reduzindo a produtividade da soja.

A maior recuperação aparente do $\mathrm{N}$ aplicado foi observada no sistema Direto na dose de $60 \mathrm{~kg} \mathrm{ha}^{-1}$, em que $52 \%$ do $\mathrm{N}$ aplicado foi recuperado pela plan- ta, enquanto que na dose de $240 \mathrm{~kg} \mathrm{ha}^{-1}$, a recuperação foi de apenas $12 \%$. A baixa recuperação aparente do $\mathrm{N}$ aplicado referente às doses mais elevadas de $\mathrm{N}$ enfatiza a importância de ajustar as aplicações de fertilizantes para o mais próximo possível da quantidade requerida pela cultura (Raij, 1991; Coelho et al., 1992). As plantas de milho também foram mais eficientes em utilizar $\mathrm{N}$, quando cultivadas sob o sistema Direto (Tabela 3), sendo esta maior eficiência verificada na dose de $60 \mathrm{~kg} \mathrm{ha}^{-1}$ de N.

$\mathrm{Na}$ Tabela 3 são apresentados o acúmulo de nutrientes (N, P, K, Ca, Mg, S e Zn) na matéria seca de grãos, para os diferentes sistemas de preparo do solo e doses de N. Observa-se que, de maneira geral, o maior acúmulo de nutrientes foi verificado nas plantas sob o sistema Direto, o que pode ser creditado ao volume de matéria seca produzido no sistema (Fig. 1). Segundo Büll (1993), as quantidades extraídas de nutrientes variam em função da produção obtida, que depende de fatores como variedade, nível e disponibilidade de nutrientes, manejo da cultura e condições climáticas, entre outros.

Observa-se que mais de $50 \%$ da quantidade total de $\mathrm{N}, \mathrm{P}, \mathrm{Mg}, \mathrm{S}$ e $\mathrm{Zn}$, acumulados na matéria seca da

TABELA 2. Nitrogênio imobilizado na microbiomassa, em duas profundidades do solo, recuperação aparente do nitrogênio aplicado e eficiência de utilização (EU) de nitrogênio para as plantas de milho cultivadas nos diferentes sistemas de preparo do solo e doses de nitrogênio ${ }^{1}$.

\begin{tabular}{|c|c|c|c|c|c|}
\hline \multirow{2}{*}{$\begin{array}{c}\text { Dose de } \\
\mathrm{N}\left(\mathrm{kg} \mathrm{ha}^{-1}\right)\end{array}$} & \multirow{2}{*}{$\begin{array}{c}\text { Sistema de } \\
\text { preparo }\end{array}$} & \multicolumn{2}{|c|}{$\mathrm{N}$ imobilizado na microbiomassa } & \multirow[t]{2}{*}{$\mathrm{N}$ recuperado ${ }^{2}$} & \multirow[t]{2}{*}{$E U^{3}$} \\
\hline & & $0-7,5 \mathrm{~cm}$ & $7,5-15 \mathrm{~cm}$ & & \\
\hline \multirow{3}{*}{0} & & \multicolumn{2}{|c|}{ - $\left(\mathrm{mg} \mathrm{kg}^{-1}\right)$} & $(\%)$ & \\
\hline & Direto & $92,23 \mathrm{a}$ & $69,12 \mathrm{a}$ & - & 1,07 \\
\hline & Disco & $36,24 b$ & $33,16 b$ & - & 1,02 \\
\hline \multirow{3}{*}{60} & Aiveca & $32,36 \mathrm{~b}$ & $28,45 b$ & - & 0,88 \\
\hline & Direto & $108,14 \mathrm{a}$ & $82,03 a$ & 52,03 & 1,51 \\
\hline & Disco & $51,12 b$ & $32,25 b$ & 26,12 & 1,14 \\
\hline \multirow{3}{*}{120} & Aiveca & $43,01 b$ & $45,26 b$ & 23,01 & 0,96 \\
\hline & Direto & $102,22 \mathrm{a}$ & $66,15 \mathrm{a}$ & 32,15 & 1,26 \\
\hline & Disco & $45,26 b$ & $34,33 b$ & 28,20 & 1,12 \\
\hline \multirow{4}{*}{240} & Aiveca & $41,32 b$ & $34,11 b$ & 17,08 & 0,96 \\
\hline & Direto & $80,19 \mathrm{a}$ & $60,24 \mathrm{a}$ & 12,11 & 1,18 \\
\hline & Disco & $40,45 b$ & $35,04 \mathrm{~b}$ & 14,21 & 0,96 \\
\hline & Aiveca & $36,12 b$ & $34,45 b$ & 10,00 & 0,92 \\
\hline
\end{tabular}

${ }_{1}^{1}$ Médias seguidas pela mesma letra, na coluna e dentro de cada dose, não diferem entre si (teste de Tukey $5 \%$ ).

$2 \mathrm{~N}$ recuperado $=(\mathrm{Nc}-\mathrm{Nsc}) 100 / \mathrm{Nac}$.

${ }^{3} \mathrm{EU}=(\mathrm{kg} \text { de matéria seca da parte aérea })^{2} /(\mathrm{mg}$ de $\mathrm{N}$ na matéria seca da parte aérea $)$. 
TABELA 3. Acúmulo de nutrientes nos grãos de plantas de milho submetidas a três sistemas de preparo do solo. Média de quatro repetições ${ }^{1}$.

\begin{tabular}{|c|c|c|c|c|c|c|c|c|}
\hline \multirow{2}{*}{$\begin{array}{c}\text { Dose de N } \\
\left(\mathrm{kg} \mathrm{ha}^{-1}\right)\end{array}$} & \multirow{2}{*}{$\begin{array}{c}\text { Sistema } \\
\text { de preparo }\end{array}$} & \multicolumn{7}{|c|}{ Acúmulo de nutrientes nos grãos ${ }^{2}$} \\
\hline & & $\mathrm{N}$ & $\mathrm{P}$ & $\mathrm{K}$ & $\mathrm{Ca}$ & $\mathrm{Mg}$ & $\mathrm{S}$ & $\mathrm{Zn}$ \\
\hline & & ---------- & -------. & ------ $(\mathrm{kg}$ & a) -- & - & ------------- & $\left(\mathrm{g} \mathrm{ha}^{-1}\right)$ \\
\hline \multirow[t]{3}{*}{0} & Direto & $37,02 \mathrm{a}(71)$ & $11,72 \mathrm{a}(91)$ & $10,96 \mathrm{a}(32)$ & $0,38 \mathrm{a}(4)$ & $5,29 a(48)$ & $3,02 \mathrm{a}(60)$ & $80,54 \mathrm{a}(54)$ \\
\hline & Disco & $35,04 a(74)$ & $12,40 \mathrm{a}(93)$ & $9,72 \mathrm{a}(31)$ & $0,34 \mathrm{a}(4)$ & $5,36 \mathrm{a}(47)$ & $2,35 b(53)$ & $69,47 \mathrm{~b}(67)$ \\
\hline & Aiveca & $33,00 \mathrm{a}(71)$ & $12,20 \mathrm{a}(86)$ & $9,90 \mathrm{a}(39)$ & $0,33 \mathrm{a}(3)$ & $4,95 \mathrm{a}(52)$ & $2,64 \mathrm{ab}(59)$ & $66,12 b(84)$ \\
\hline \multirow[t]{3}{*}{60} & Direto & $61,01 \mathrm{a}(73)$ & $23,93 \mathrm{a}(91)$ & $19,37 \mathrm{a}(37)$ & $0,57 \mathrm{a}(5)$ & $9,68 \mathrm{a}(62)$ & $3,99 \mathrm{a}(56)$ & $124,54 a(35)$ \\
\hline & Disco & $46,00 \mathrm{~b}(73)$ & $18,13 b(92)$ & $10,05 b(26)$ & $0,44 b(5)$ & $7,08 \mathrm{~b}(52)$ & $3,54 \mathrm{a}(58)$ & $101,33 b(73)$ \\
\hline & Aiveca & $44,53 b(74)$ & $17,13 b(92)$ & $11,95 b(34)$ & $0,41 \mathrm{~b}(3)$ & $7,00 \mathrm{~b}(59)$ & $2,88 \mathrm{~b}(60)$ & $97,60 \mathrm{~b}(76)$ \\
\hline \multirow[t]{3}{*}{120} & Direto & $69,01 \mathrm{a}(76)$ & $24,05 \mathrm{a}(91)$ & $19,35 \mathrm{a}(34)$ & $0,59 a(7)$ & $9,97 \mathrm{a}(64)$ & $4,11 \mathrm{a}(60)$ & $145,80 \mathrm{a}(46)$ \\
\hline & Disco & $58,04 \mathrm{ab}(77)$ & $21,74 \mathrm{ab}(95)$ & $13,27 \mathrm{a}(31)$ & $0,49 b(6)$ & $9,39 a(55)$ & $4,45 \mathrm{a}(70)$ & $136,47 \mathrm{a}(87)$ \\
\hline & Aiveca & $51,00 \mathrm{~b}(76)$ & $18,94 b(83)$ & $13,98 \mathrm{a}(38)$ & $0,45 \mathrm{~b}(4)$ & $7,67 b(64)$ & $4,06 \mathrm{a}(66)$ & $100,06 \mathrm{~b}(76)$ \\
\hline \multirow[t]{3}{*}{240} & Direto & $60,01 \mathrm{a}(75)$ & $24,35 \mathrm{a}(94)$ & $24,35 \mathrm{a}(43)$ & $0,53 a(5)$ & $10,08 \mathrm{a}(64)$ & $3,71 b(56)$ & $147,04 \mathrm{a}(54)$ \\
\hline & Disco & $59,00 \mathrm{a}(73)$ & $16,88 \mathrm{~b}(88)$ & $16,88 b(38)$ & $0,46 b(6)$ & $10,03 a(61)$ & $3,65 b(61)$ & $87,53 b(61)$ \\
\hline & Aiveca & $54,04 \mathrm{a}(76)$ & $18,48 \mathrm{ab}(36)$ & $14,08 \mathrm{~b}(36)$ & $0,44 b(4)$ & $7,92 b(69)$ & $4,40 \mathrm{a}(69)$ & $111,50 \mathrm{~b}(80)$ \\
\hline
\end{tabular}

${ }_{1}^{1}$ Médias seguidas pela mesma letra na coluna, dentro de cada dose, não diferem entre si (teste de Tukey 5\%).

${ }^{2}$ Número entre parênteses representa a porcentagem do nutriente em relação ao acumulado pela parte aérea.

parte aérea das plantas de milho, encontra-se nos grãos (Tabela 3). Dessa forma, mesmo com a manutenção da palhada na área de produção, a reposição desses nutrientes em cultivos seguintes se faz necessária em decorrência das grandes quantidades que são exportadas pelos grãos, principalmente de $\mathrm{N}$, que, além desta exportação, é facilmente perdido no sistema em função de sua dinâmica no solo (Raij, 1991).

De modo geral, a translocação de nutrientes para os grãos, em ordem decrescente, foi a seguinte: $\mathrm{N}$ (71-77\%); P (77-86\%); K (26-43\%); Ca (3-7\%); Mg (47-69\%); S (53-77\%) e Zn (35-87\%). Esses percentuais corraboram os dados obtidos por Vasconcellos et al. (1983), com relação a esta cultura.

Independentemente do sistema de preparo do solo e das doses de $\mathrm{N}$, a quantidade de nutrientes acumulada pela cultura, quanto aos macronutrientes, foi, em ordem decrescente, a seguinte: $\mathrm{N}>\mathrm{K}>$ $\mathrm{P}>\mathrm{Mg}>\mathrm{Ca}>\mathrm{S}$. Do total dos macronutrientes acumulados pela parte aérea, o $\mathrm{N}$ correspondeu a mais de $40 \%$ do total, enquanto o $\mathrm{S}$ correspondeu a menos de 4\%. Segundo Mengel \& Kirkby (1987), o N é o nutriente mineral mais exigido pelas plantas, uma vez que o elemento participa da composição de vários compostos, como proteínas, enzimas, bases nitrogenadas, coenzimas, pigmentos e vitaminas.

\section{CONCLUSÕES}

1. O sistema de plantio direto proporciona maior produção de grãos e de palhada em relação ao sistema convencional com arado de disco e convencional com arado de aiveca.

2. As doses de $\mathrm{N}$, para a produção máxima de grãos, são, respectivamente, 147, 156 e $168 \mathrm{~kg} \mathrm{ha}^{-1}$ nos sistemas de plantio direto, convencional com arado de disco e convencional com arado de aiveca.

3. Em dose superior a $60 \mathrm{~kg} \mathrm{ha}^{-1}$ de $\mathrm{N}$, ocorre menor eficiência de utilização e recuperação do $\mathrm{N}$ aplicado, por parte das plantas de milho.

\section{REFERÊNCIAS}

BÜLL, L.T. Nutrição mineral do milho. In: BÜLL, L.T.; CANTARELLA, H. (Eds.). Cultura do milho: fatores que afetam a produtividade. Piracicaba: POTAFOS, 1993.301p. 
CARDOSO, A.N. Manejo e conservação do solo na cultura da soja. In: ARANTES, N.E.; SOUZA, P.I. de M. de. (Eds.). Cultura da soja nos cerrados. Piracicaba: POTAFOS, 1993. p.71-104.

CENTURION, J.F.; DEMATÊ, J.L.I. Efeitos de sistemas de preparo nas propriedades físicas de um solo sob cerrado cultivado com soja. Revista Brasileira de Ciência do Solo, Campinas, v.9, p.263-266, 1985.

COELHO, A.M.; FRANÇA, G.E. de; BAHIA FILHO, A.E.C.; GUEDES, G.A.A. Doses e métodos de aplicação de fertilizantes nitrogenados na cultura do milho sob irrigação. Revista Brasileira de Ciência do Solo, Campinas, v.16, p.61-67, 1992.

EMBRAPA. Centro Nacional de Pesquisa de Milho e Sorgo (Sete Lagoas, MG). Recomendações técnicas para o cultivo do milho. Sete Lagoas: Embrapa-CNPMS / Brasília: Embrapa-SPI, 1993. 204p.

FOLLETT, R.F.; SCHIMEL, D.S. Effect of tillage practices on microbial biomass dynamics. Soil Science Society of America. Journal, Madison, v.53, p.1091-1096, 1989.

GREGORICH, E.G.; ELLERT, B.H.; DRURY, C.F.; LIANG, B.C. Fertilization effects on soil organic matter turnover and corn residue $\mathrm{C}$ storage. Soil Science Society of America. Journal, Madison, v.60, p.472-476, 1996.

HOFFMANN, C.R. Nutrição mineral e crescimento da braquiária e do colonião, sob influência das aplicações de nitrogênio, fósforo, potássio e enxofre em latossolo da região Noroeste do Paraná. Lavras: ESAL, 1992. 204p. Tese de Mestrado.

HOLANDA, F.S.R. Efeito de sistema de preparo do solo e sucessão de culturas: 1 . Estratificação de fósforo, potássio, $\mathrm{pH}$ e matéria orgânica no perfil do solo; 2. Absorção de P, K pela cultura do milho (Zea mays L.). Lavras: UFLA, 1996. 86p. Tese de Doutorado.

HSIEH, Y.P. Pool size and mean age of stable soil organic carbon in cropland. Soil Science Society of America. Journal, Madison, v.56, p.460-464, 1992.

HUBBARD, V.; JORDAN, D. Nitrogen recovery by corn from nitrogen-15 labeled wheat residues and intact roots and soil. Soil Science Society of America. Journal, Madison, v.60, p.1405-1410, 1996.

JANSSEN, B.H. A simple method for calculating decomposition and accumulation of young soil organic matter. Soil Science, The Hague, v.76, p.297-304, 1984.

KER, J.C.; PEREIRA, N.R.; CARVALHO JÚNIOR, W. de; FARIA, A. de C. Cerrados: solos, aptidão e potencialidade agrícola. In: SIMPÓSIO SOBRE MANEJO E CONSERVAÇÃO DO SOLO NO CERRADO, 1., 1990, Goiânia. Anais. Campinas: Fundação Cargill, 1992.p.1-31.

LIANG, B.C.; MACKENZIE, A.F. Changes in soil organic carbon and nitrogen after six years of corn production. Soil Science, Baltimore, v.153, p.307313, 1992.

MARIA, I.C. de; CASTRO, O.M. de. Fósforo, potássio e matéria orgânica em um Latossolo Roxo, sob sistemas de manejo com milho e soja. Revista Brasileira de Ciência do Solo, Campinas, v.17, p.465-470, 1993a.

MARIA, I.C. de; CASTRO, O.M. de. Potássio e matéria orgânica em um Latossolo Roxo, sob sistemas de manejo com milho e sorgo. Revista Brasileira de Ciência do Solo, Campinas, v.17, p.471-477, 1993 b.

MENGEL, K.; KIRKBY, E.A. Principles of plant nutrition. Bern: International Potash Institute, 1987. $687 \mathrm{p}$.

MORRISON, J.E.; CHICHESTER, F.W. Tillage system effects on soil and plant nutrient distribution on vertisols. Journal of Production in Agriculture, St. Paul, v.7, n.3, p.364-375, 1994.

MUZILLI, O. Fertilidade do solo em plantio direto. In: FUNDAÇÃO CARGILL (Campinas, SP). Atualização em plantio direto. Campinas, 1985. p.147160.

PANG, X.P.; LETEY, J.; WU, L. Irrigation quatity and uniformity and nitrogen application effects on crop yield and nitrogen leaching. Soil Science Society of America. Journal, Madison, v.61, p.257-261, 1997.

PEREIRA, J.; PERES, J.R.R. Manejo da matéria orgânica. In: GOEDERT, W.J. (Ed.). Solos dos cerrados: tecnologias e estratégias de manejo: São Paulo: Nobel, 1986. p.261-284.

PINAZZA, L.A. Perspectiva da cultura do milho e do sorgo no Brasil. In: BÜLL, L.T.; CANTARELLA, H. (Eds.). Cultura do milho: fatores que afetam a produtividade. Piracicaba: POTAFOS, 1993.301p.

Pesq. agropec. bras., Brasília, v.34, n.9, p.1691-1698, set. 1999 
RAIJ, B. van. Nitrogênio. In: RAIJ, B. van. (Ed.). Fertilidade do solo e adubação. Piracicaba: POTAFOS, 1991. p.163-179.

ROSCOE, R. Atividade da urease em um Latossolo Vermelho-Escuro de Sete Lagoas, MG, cultivado com milho, sob diferentes métodos de preparo do solo. Lavras: UFLA, 1997. 50p. Dissertação de Mestrado.

SIDDIQI, M.Y.; GLASS, A.D.M. Utilization index: a modified approach to the estimation and comparison of nutrient efficiency in plants. Journal of Plant Nutrition, New York, v.4, n.3, p.298-302, 1981.

SIDIRAS, N.; PAVAN, M.A. Influência do sistema de manejo do solo no seu nível de fertilidade. Revista
Brasileira de Ciência do Solo, Campinas, v.9, p.249254, 1985.

SIQUEIRA, J.O.; MOREIRA, F.M.S.; GRISI, B.M.; ARAÚJO, R.S. Microrganismos e processos biológicos do solo: perspectiva ambiental. Brasília: EmbrapaSPI, 1994. 142p. (Embrapa-CNPAF. Documentos, 45).

VASCONCELLOS, C.A.; BARBOSA, J.V.A.; SANTOS, H.L. dos; FRANÇA, G.E. de. Acumulação de massa seca e de nutrientes por duas cultivares de milho com e sem irrigação suplementar. Pesquisa Agropecuária Brasileira, Brasília, v.18, n.8, p.887901, ago. 1983. 